\title{
OBRAS DE RESTAURACIÓN Y TERMINACIÓN DE LA FACHADA DEL ÁNGULO SUROESTE DE LA CATEDRAL DE SEVILLA. EL PROYECTO DE FRANCISCO JAVIER DE LUQUE
}

\author{
POR M.aa del Valle Gómez de Terreros Guardiola
}

Las obras de terminación de la fachada del ángulo suroeste de la Catedral de Sevilla despertaron cierta polémica en los círculos artísticos hispalenses durante las primeras décadas del siglo XX. Por ello, el proyecto ejecutado por Francisco J. de Luque para tal fin sirve como botón de muestra de los criterios de restauración vigentes en el referido período, tan ligados a la mentalidad arquitectónica de un momento crucial para el arte sevillano.

The works for the termination of the southwest façade of the Sevillian Cathedral brought about a certain controversy in local artistic circles during the first decades of the 20th century. For this reason, Francisco J. de Luque's design serves as an example of the restoration theories of those times, which so closely reflected the architectural mentality of a fundamental period of Sevillian art.

Del 6 de mayo de 1921 data el "Proyecto y presupuesto de obras de restauración y terminación de la fachada de las dependencias de la catedral de Sevilla situadas entre la puertas de San Miguel y San Cristóbal", firmado por el arquitecto Francisco Javier de Luque y López y conservado en el Archivo General de la Administración Civil del Estado ${ }^{1}$. Es éste un trabajo que merece cierta atención,

1. Archivo General de la Administración Civil del Estado, Secc. Educación y Ciencia, Leg. 13.225-8, Caja 4.890. 
no sólo por el lógico interés que despierta cualquier intervención en tan monumental edificio, sino también como botón de muestra de los criterios de restauración vigentes en el primer tercio del siglo $\mathrm{XX}$, tan ligados a la mentalidad arquitectónica de un momento crucial para el arte sevillano.

De lo ya conocido sobre la fachada de las dependencias que ocupan el ángulo suroeste de la Catedral hispalense ${ }^{2}$, cabe simplemente recordar algunos datos precisos para la posterior comprensión del proyecto que se va a exponer. La construcción se inició en 1760 siguiendo un proyecto, realizado tres años antes por José de Herrera, cuya composición se inspiraba en el vecino exterior de la zona de la sacristía mayor del Templo. El nuevo muro quedó caracterizado por contar con dos cuerpos de ventanas regularmente dispuestas en toda su superficie frente a la parcial cerrazón exterior del ya construido, que disponía de escasos huecos, dispuestos a considerable altura, en su flanco Sur. Sin más noticias en los Autos Capitulares que las referentes al comienzo de las obras, éstas se paralizaron al finalizarse el primer piso de vanos ${ }^{3}$. Así fue descrito y representado el cerramiento en la Descripción Artística de la Catedral de Sevilla que publicó J. A. Ceán Bermúdez en 1804, quien ya apuntó que en su elaboración,

"...se copió la arquitectura del otro muro antiguo, que circunda las sacristías, la sala capitular y la contaduría mayor. Paró esta obra antes de llegar a la mitad de su altura y permanece en este estado con veinte y seis medias pilastras, diez y nueve ventanas de elegante forma y con frontispicios romanos. El espacio que rodea este muro servía para obrador de canteros, y se acaba de aprovechar, construyendo en él dos o tres patios pequeños, sala de rentas, archivo, (el más bien ordenado que se conoce en España); lugar común y otras oficinas, con dos puertas junto a la Lonja

2. Vid. LUNA FERNÁNDEZ ARAMBURU, R. y SERRANO BARBERÁN, C.: Planos y dibujos del archivo de la Catedral de Sevilla (siglos XVI-XX), Sevilla, 1986, pp. 45-51; FALCÓN MÁRQUEZ, T.: La Catedral de Sevilla. Estudio arquitectónico. Sevilla, 1980, pp. 98-99 y 111; en esta última página aparece publicada una fotografía de las obras de terminación de la fachada sur fechada en 1925. Fotografías similares de estas obras se conservan en el Laboratorio de Arte de la Universidad de Sevilla. En la vista de la fachada Sur de la Catedral de Sevilla realizada por Matías de Arteaga y publicada en la obra de Fernando de la TORRE FARFÁN Fiestas de la S. Iglesia Metropolitana y Patriarcal de Sevilla, al nuevo culto del Señor Rey S. Fernando el Tercero de Castilla y de León, Sevilla, 1671, aparece el edificio sin la construcción que estudiamos; véase el catálogo de J. PORTUS en Iconografia de Sevilla, 1650-1790, Madrid, 1989, pp. 269 y 271.

3. LUNA FERNÁNDEZ ARAMBURU y SERRANO BARBERÁN, C., op. cit., pp. 45-46. Véanse en el Archivo de la Catedral de Sevilla las actas capitulares correspondientes a las juntas celebradas el 16 de noviembre de 1757 y 15 de septiembre de 1760 , libros n.. 124 y 126, fols. 223 y $92 v$. respectivamente. En la última página citada se comenta y aprueba el proyecto del maestro cantero Joseph de Herrera, el cual contaba con ventanas altas y bajas por si en el interior del edificio se quisieran labrar algunas piezas que necesitasen de mucha luz y para que dicha fachada tuviera exteriormente más hermosura, aunque por ello no se conformase con el lienzo del muro del otro lado. 
para comodidad y servicio del público, sin necesidad de pasar como antes por la iglesia, para lo que contribuyó el referido arzobispo D. Alonso Marcos de Llanes con 90.000 reales vellón ${ }^{4}$."

En dicho estado debió conservarse la construcción -al menos en su exteriorhasta principios del siglo $\mathrm{XX}$, cuando el a la sazón arquitecto director de obras de restauración de la Catedral, Joaquín de la Concha Alcalde, denunció su “aspecto poco decoroso y digno que contrasta abiertamente con el aspecto suntuoso del resto del monumento", considerando en consecuencia apremiante la terminación del ángulo suroeste de la Catedral. Pero antes de acometer dichas obras era preciso, dado su aspecto ruinoso, restaurar lo existente, especialmente el basamento y el zócalo. Y, aunque la restauración se acometió entre 1913 y 1917, ya en 1915 varios miembros de la Junta de Obras de la Catedral de Sevilla, el arquitecto Mariano González Rojas y el pintor Virgilio Mattoni -ambos, miembros de la Comisión local de Monumentos- entre otros, protestaron contra el proyecto de terminación de la fachada que se proponía formular de la Concha. Este pretendía -como había sido planteado desde el siglo XVIII- armonizar dicha fábrica con la contigua, es decir, la lindante con la sacristía mayor. La discusión se centró en la finalización de una construcción que, a juicio de aquéllos, merecía más desaparecer que conservarse. Aún así, de la Concha diseñó, en 1918, un proyecto consistente en la adición de un segundo piso al existente. Pero a raíz de su fallecimiento, ese mismo año, las obras de la Catedral pasaron a manos de Francisco Javier de Luque ${ }^{5}$.

El nuevo arquitecto, tras su nombramiento como director de las obras de conservación y restauración de la Catedral de Sevilla, manifestó su intención de "terminar obras cuya construcción quedó en suspenso, como ocurre con la porción de fachada de estilo greco-romano comprendida entre las puertas de San Miguel y San Cristóbal" ' 6 . Luque, consciente de las dificultades a las que iba a enfrentarse, estudió los antecedentes de la obra, precisando en su propio trabajo, fechado como se ha dicho en 1921, que no se conservaban planos ni detalles del proyecto primitivo y que la fábrica seguía, en la fecha, construida hasta la mitad de su altura, contando con las mismas "veintiséis medias pilastras -en los planos

4. CEÁN BERMÚDEZ, J.A.: Descripción artística de la Catedral de Sevilla, Sevilla, 1804 (ed. 1863), p. 102. Aparece una estampa de la fachada Sur de la Catedral de M. Carmona, también reproducida en Iconografía de Sevilla (1790-1868), Madrid, 1991, p. 351.

5. LUNA FERNÁNDEZ ARAMBURU, R. y SERRANO BARBERÁN, C., op. cit., pp. 46-47. La cita procede de una memoria del arquitecto, referente a los trabajos ya realizados y a los que se proponía emprender, fechada en 1907 y conservada en el Archivo de la Catedral de Sevilla.

6. A.G.A. Memoria del proyecto de obras de restauración y terminación de la fachada de las dependencias de la Catedral de Sevilla situadas entre las puertas de San Miguel y San Cristóbal, obra de Francisco Javier de Luque, Sevilla, 6 de mayo de 1921. Vid. nota 1. 
aparecen veintisiete-, diecinueve ventanas de elegante forma y frontispicios romanos" mencionados por Ceán. Ello, unido a la inexistencia en su memoria de alusión alguna a los trabajos de su antecesor en el cargo, parece indicarnos que en poco o nada afectó al alzado la restauración por aquél efectuada, salvando los aspectos constructivos y refiriéndonos meramente a los creativos. Tan sólo queda la duda de si las molduras mixtilíneas existentes sobre los vanos fueron realizadas o retocadas bajo su dirección ${ }^{7}$. La construcción existente, según Luque, denotaba claramente, por su estilo, por las proporciones dadas a su basamento $y$ a las inacabadas pilastras, por la faja decorada que las atravesaba y por la traza de sus ventanas y frontispicios, que en su diseño se había buscado armonizarla con respecto al alzado que ocupa el lado derecho de la puerta de San Cristóbal, aunque dándole "sello propio y clara diferenciación" 8 .

El arquitecto relató además en su memoria cómo, desde hacía tiempo, era aquélla una obra que preocupaba en Sevilla a cuantas instituciones y personas amantes de las Artes estaban interesadas por los monumentos de la ciudad. La fábrica, sin terminar, no mostraba un aspecto adecuado a la zona más característica de la capital andaluza, parecía denotar olvido y la falta de atención obligada en sus circunstancias. Así, en el deseo común de solucionar el asunto, se habían decantado tres diferentes propuestas, que recogió Francisco Javier de Luque, si bien, anticipando su rechazo hacia todas ellas. A saber:

- Proseguir la fábrica y elevarla hasta la altura que parecía demandar su parte inferior, con la única dificultad del posible acierto en "completar su traza lo más ajustada posible a la idea de su autor". Ese había sido el propósito de Joaquín de la Concha, reconociendo Luque que, aparte del elevado coste de dicha propuesta, con ella perdía la Catedral el único punto de vista desde el que el edificio mostraba al exterior su primitiva estructura.

- Buscar un posible remate que, sin elevar ni una hilada más la fábrica, diera la impresión de que la fachada estaba terminada. Esta opción fue inmediatamente rechazada ante la imposibilidad de hallar medio alguno de finalizar a la mitad de su altura una construcción iniciada con dobles proporciones.

- Derribar dicha construcción. Para Luque esta tercera vía, si bien era mejor que las anteriores, ofrecía los inconvenientes de la desaparición de "una bella

7. Véanse los planos números 71 al 76 del Archivo de la Catedral de Sevilla. En concreto, los números 73 y 76, en los que la referida moldura difiere ligeramente. El primero ha sido atribuido a De la Concha y el segundo a Luque; vid. LUNA FERNÁNDEZ ARAMBURU, R. y SERRANO BARBERÁN, C., op. cit., pp. 50-51.

8. A.G.A. Memoria del proyecto de obras de restauración y terminación de la fachada de las dependencias de la Catedral de Sevilla situadas entre las puertas de San Miguel y San Cristóbal, obra de Francisco Javier de Luque, Sevilla, 6 de mayo de 1921. Vid. nota 1.

9. Ibid. 
composición digna al fin y al cabo de respeto y de dejar al Cabildo sin unas dependencias que hoy le son absolutamente indispensables 9 ."

Tras estudiar detenidamente el asunto el arquitecto expuso su propia solución al problema, base definitiva del proyecto: "respetar lo construido sacando de su composición el único partido posible para que resulte una obra acabada". Buscó una disposición de motivos derivada de la existente, manteniendo su "carácter y estilo" y modificó -redujo- las proporciones originarias, rematando finalmente el conjunto con una balaustrada. Con todo ello, apenas se elevaría el edificio. En consecuencia, modificó -achicó- las pilastras, respetó los ventanales con sus remates, las dimensiones de los entrepaños, ciertas molduras, obteniendo por simple rebajo o retranqueo del paramento del zócalo las nuevas y necesarias formas en la zona inferior ${ }^{10}$. Resumiendo, trató de convertir un orden gigante en otro simple, acorde con la altura a la que iba a quedar reducida la fábrica, con el fin de dar un aspecto unitario al conjunto, es decir, que finalmente apareciera como producto de una única idea bien definida, como obra de una sola mano.

Esta explicación iba lógicamente acompañada por los pertinentes diseños y algunas fotografías. En concreto cuenta el proyecto con cuatro planos: uno de "detalles de la planta" (Lám. 1); dos alzados, correspondientes al "estado actual" y a las "obras de reforma" (Láms. 2 y 3), que reproducimos, por la anchura de los originales, divididos en tres partes cada uno; y otro de detalles, en el que junto a dos secciones aparece un estudio comparativo del edificio antes y tras la reforma (Lám. 4). Además cuenta el trabajo de Luque con tres fotografías: una del estado del edificio antes de su terminación (Lám. 5); otra del lado derecho de la puerta de San Cristóbal; y la última, una imagen retocada en la que se pueden comparar el "estado actual" de la construcción y el "nuevo proyecto" (Lám. 6). A esta documentación gráfica hemos añadido una fotografía actual del edificio que permita comparar el proyecto de Luque con la construcción existente (Lám. 7).

Pero no sólo se conservan la memoria y la documentación gráfica, sino también las condiciones de las obras, las mediciones y el presupuesto de ejecución material, gracias a los que podemos apuntar ciertos detalles de los trabajos a ejecutar. Se debía relabrar la piedra existente, sacando las nuevas molduras y los perfiles marcados en los planos; todos aquellos sillares que al ser relabrados se inutilizasen, serían sustituidos por otros nuevos, elaborados con piedra procedente de la canteras del Puerto de Santa María; y la misma piedra sería utilizada para la elevación de las últimas hiladas y en la elaboración de la crestería y los pináculos. La elección de dichas canteras estaba condicionada por el origen del material de la edificación existente. Se insistió en el proyecto en que "no será

10. Ibid. Todo ello se presupuestó en $297.408,41$ pesetas. 
heladiza, y estará exenta de coqueras, pelos, ni cualquier otro defecto o gabarro que pudiera perjudicar su aspecto o resistencia" ${ }^{11}$.

La elaboración consistiría en el retundido de los muros existentes y la obtención con ello de nuevos perfiles. Aparecerían nuevas molduras en el zócalo, modificándose las basas y los fustes de las pilastras, haciendo desaparecer el corte inicial entre estos últimos y sus basamentos, definiéndose así un orden simple de menor tamaño al primitivo. También eran precisos el desbaste de la moldura de repisa de los huecos y la ejecución de los perfiles pertinentes tras semejante modificación; la extracción de nuevas molduras en los tableros proyectados bajo los huecos y entre éstos y las pilastras; mas el desmonte de los últimos sillares de las últimas para completar su molduración superior. Aparte de las reformas apuntadas en el muro existente, había que añadir los sillares labrados precisos para completar la ornamentación superior inacabada, el entablamento, la cornisa, las gárgolas, la balaustrada -con sus pilares cajeados y balaustres torneados, zócalos y pasamanos-, y los pináculos, junto con toda la labra y ornamentación que en los planos reflejan los elementos citados ${ }^{12}$.

El proyecto de Francisco Javier de Luque fue remitido, para su aprobación, al Ministerio de Instrucción Pública y Bellas Artes, desde donde pasó a la Real Academia de Bellas Artes de San Fernando a fin de que ésta emitiera el pertinente informe. Por este dictamen, fechado el 17 de noviembre de 1922 y publicado en el Boletín de dicha Corporación ${ }^{13}$, nos es posible conocer la polémica abierta por el deseo del Cabildo catedralicio de finalizar la fábrica que nos ocupa.

11. A.G.A. Condiciones de ejecución del proyecto. Vid. nota 1. En lo referente al tipo de piedra utilizada en las dependencias del ángulo suroeste de la Catedral hemos de tener en cuenta, aparte de los diferentes retoques sufridos por la fábrica a lo largo de su existencia, las facturas que hemos podido localizar de las obras. En efecto, en las "Cuentas de las obras de la terminación de la fachada Sur. Año 1924-25", en la que se especifica que son "obras de terminación de la fachada sur del edificio adosado a la Catedral", constan varios recibos de "piedra de sillería franca del Puerto de Santa María"; otros, de febrero de 1925, por piedra de sillería de Monovar y seis bolas de piedra martelilla; y otro recibo, de abril de 1925, de siete bolas y siete balaustres de piedra martelilla. En otros estudios realizados sobre la misma edificación se cita la piedra de Espera como material mayoritariamente empleado: véase la tesis doctoral inédita de M. ALCALDE MORENO, titulada Sintomatología de alteraciones de las catedrales de Sevilla, Cádiz y Almería, Universidad de Sevilla, 1989; igualmente la de M.A. BELLO LÓPEZ: Caracterización y estado de alteración química de los materiales empleados en la construcción de la Catedral de Sevilla, Sevilla, 1988; al parecer, el tipo de degradación que sufre la piedra de dicha fachada, bastante irregular, se corresponde con la que suele afectar a la piedra de Espera.

12. A.G.A. Presupuesto de ejecución material. Vid. nota 1.

13. "Informe sobre el proyecto de obras para la terminación de la fachada del cuerpo de edificio adosado a la del Mediodía de la Catedral de Sevilla", Boletín de la Real Academia de Bellas Artes de San Fernando, t. XVI, año 1922, n.. 64, 31 de diciembre de 1922, pp. 194-198. Aparece como ponente del informe Ricardo VELÁZQUEZ BOSCO, siendo dirigido al Ministro de Instrucción Pública y Bellas Artes por Manuel Zabala y Gallardo, como Secretario General. 
Según el referido texto, la Academia de Bellas Artes de Sevilla había solicitado el apoyo de la madrileña a su protesta por tal iniciativa. Se creía en la Institución hispalense que las obras iban a consistir en la construcción de un segundo cuerpo sobre el existente e inconcluso, lo que, a su juicio, perjudicaría notablemente al monumento más importante de la ciudad. Uno de los motivos aducidos fue que la zona del ángulo suroeste era la única desde la que -como apuntó Luque en su proyecto- se percibía la fábrica ojival; de realizarse una segunda planta, dicha vista quedaría para siempre oculta. Además, se consideraba que el resultado sería "una construcción pesada y de pésimo gusto artístico, pues parece que habrá que seguirse en ella el orden y estilo de lo hoy existente". Para finalizar, ni siquiera creía la referida Corporación sevillana en las razones que aducían la necesidad de dichas dependencias del Cabildo Metropolitano, pensando que éste ya contaba con "casa de sobra". Consciente de la difícil solución que tenía el asunto, prefería que el edificio quedara sin concluir antes que ocultar aún más la Catedral, aceptando, a lo sumo, que se le diera "el remate estrictamente indispensable, que alterase en poco o casi nada la altura que actualmente tiene la fábrica". De ningún modo admitiría la elevación de un segundo cuerpo, "aunque se aleguen en pro de esta idea razones de armonía y regularidad de la edificación" ${ }^{14}$.

Lógicamente, lo publicado en el Boletín de la Academia de San Fernando parece referirse a la opinión que a su homónima sevillana le merecía la idea proyectada por de la Concha y evidencia que cuando se redactó este informe la Institución local desconocía el proyecto de Luque, que se redujo, al fin y al cabo, a la solución por ella propuesta. Ello motivó que acudiéramos al archivo de la Real Academia de Bellas Artes de Santa Isabel de Hungría con el propósito de conocer la fecha en la que se acordó emitir su protesta ante la iniciativa del Cabildo Catedral, verificándose que fue el 20 de junio de 1918 cuando se decidió dirigir oficios al Cabildo Eclesiástico y a la Academia de San Fernando "protestando de las obras que se proyectaban en el lado mediodía de la Catedral de Sevilla, limitándolas al remate o cornisa estrictamente indispensable" ${ }^{15}$. Por otra parte, en dichas actas no aparece recogida ninguna actitud contraria a las propuestas del autor definitivo del proyecto, quien además, en 1925, fue nombrado académico correspondiente en Madrid ${ }^{16}$.

14. Ibid, pp. 194-195.

15. Archivo de la Real Academia de Bellas Artes de Santa Isabel de Hungría, Libro de Actas 1901-1920, Junta General ordinaria celebrada el 20 de junio de 1918.

16. Ibid. Libro de Actas 1921-1932, Junta General celebrada el 15 de junio de 1925. La propuesta fue presentada por Adolfo Rodríguez Jurado, acordándose por unanimidad y haciéndose mención de la notable conferencia del "ilustre arquitecto sevillano" sobre las vidrieras de la Catedral de Sevilla. 
Tal como figuraba en la aludida acta de la Academia, también se remitió al Cabildo Catedral la pertinente protesta, que se vio en la junta celebrada el 3 de julio de 1918. Tal día se leyó la oportuna comunicación en contra de las obras proyectadas de construcción de un segundo cuerpo en la zona del mediodía de la Catedral, y solicitando, en consecuencia, que el Cabildo influyera en hacer fracasar tal empresa. Pero el Cabildo acordó contestar, simplemente, "que no tenía noticia ninguna del proyecto de referencia" ${ }^{17}$. Y debía ser así, porque no se volvió a tratar del tema hasta llegado el día 3 de noviembre de 1920. En dicha fecha, Luque debía ya haber desarrollado sus diseños dado que, por una fotografía por él entregada al Sr. Mayordomo, "el Cabildo podría apreciar cómo ha de quedar la parte de la Santa Iglesia que da a la Lonja una vez que quede terminado su proyecto de poner una balaustrada artística a aquella parte" ${ }^{18}$. Se le agradeció al arquitecto su atención, quedando los capitulares complacidos con su trabajo. Dicha fotografía no debe ser otra que la composición que se conserva en el Archivo General de la Administración, junto con el proyecto, que en estas páginas reproducimos.

Continuando con el texto de protesta de la Academia sevillana, esta institución exponía además que

"En los momentos presentes, con aplauso y satisfacción de todos los sevillanos amantes de las Artes y de la cultura, se están viendo desaparecer, no sin grandes trabajos, vencidos por fortuna, el sinnúmero de casuchas y dependencias que afeaban el gran patio de la Mezquita sevillana que llamamos de los Naranjos, habiendo quedado ya al descubierto el soberbio arco de ojiva túmida, oculto por la Sacristía de la Hermandad de la Virgen de la Granada, y los demás que se irán descubriendo a medida que los derribos adelanten; obras que, una vez terminadas, nos darán idea, siquiera sea algo imperfecta, de lo que fue tan magnífica construcción de origen almohade ${ }^{19}$."

En consecuencia, se consideraba ilógico que paralelamente a que se siguieran criterios tendentes a devolver una parte de la Catedral a su estado originario, se transformara la fábrica gótica ocultándola. Era cierto que en el Patio de los Naranjos se habían demolido "construcciones modernas" adosadas tanto su fa-

17. Archivo de la Catedral de Sevilla, Actas Capitulares, Cabildo celebrado el 3 de julio de 1918, libro 231 , fols. $44 \mathrm{v}-45$.

18. Ibid. Cabildo celebrado el 3 de noviembre de 1920, libro 231, fols. 199-199v.

19. "Informe sobre el proyecto...", op. cit., pp. 195-196. 
chada Norte, como a la Sur, con los consecuentes problemas de reubicación de dependencias allí localizadas ${ }^{20}$.

La Academia de San Fernando consideró "justas y atinadas" las razones aducidas desde Sevilla, dados los criterios entonces vigentes en la restauración de monumentos:

"En todas partes se ha llevado a cabo, en lo posible, la demolición de las construcciones adosadas que impedían apreciar y admirar en todo su valor artístico las hermosas obras maestras de la Arquitectura de la Edad Media, no menos admirables que las más preciadas joyas de la Arquitectura clásica, a las que en nada ceden y a las que a nadie ocurriría hoy ocultar adosando a ellas vulgares construcciones. Este principio se ha llevado, sin embargo, demasiado lejos en algunos monumentos, pudiendo citar entre ellos la iglesia de San Sernín (San Saturnino), de Toulouse, cuya restauración estuvo encomendada a Viollet le Duc, en la que hoy puede admirarse la característica armonía de su típica composición; pero esto se ha hecho a costa de haber destruido construcciones a ella adosadas de gran interés artístico, extremo a que esta Academia con su voto no autorizaría llegar nunca, lamentando sólo que en lo que a la Catedral de Sevilla se refiere, se trate del caso contrario, de ocultar en lugar de descubrir o despejar;,..." 21

Por ello la Academia de San Fernando no podía ver con optimismo las obras a realizar en el Templo hispalense, aunque considerase, como su homónima sevillana, la difícil resolución de un caso en que todas las opiniones eran atendibles. Aplicando los criterios antes expuestos la Academia madrileña añadió en su escrito ciertas consideraciones generales sobre el edificio, manifestando que hubiese sido deseable

“... que, a ser posible, se demolieran aquellas partes que interior y exteriormente carezcan por completo de todo valor artístico, permitiendo de esta suerte contemplar la composición de aquel grandioso templo en la parte que llegó a ejecutarse con sujeción al primitivo proyecto del que no se realizó más que la parte del cuerpo de las naves, quedando ya de hecho destruido en su composición al levantarse la Capilla Real..." ${ }^{22}$.

20. Archivo de la Catedral de Sevilla, Actas Capitulares, cabildos celebrados los días 4 de abril, 10 de mayo, 21 de octubre y 11 de noviembre de 1918; 19 de marzo de 1919, libro 231, fols. 23, 32v$33,66 \mathrm{v}, 70$ y 100 .

21. "Informe sobre el proyecto...", op. cit., pp. 196-197.

22. Ibid., p. 196. 
Volviendo al proyecto concreto que nos ocupa, consideraba que la demolición de la fábrica existente era inviable dado que el Cabildo Catedral nunca daría su conformidad para ello. El Alcalde de Sevilla también había expresado su deseo de que el asunto se solucionase para que desapareciera el desagradable aspecto que presentaba el edificio sin terminar en la parte más monumental de la ciudad que, precisamente en aquellos momentos, se estaba reformando y en la que "tan gallarda muestra de su valer están dando los Arquitectos de Sevilla". En consecuencia, dada la imposibilidad de su derribo, solicitaba que dichas construcciones se terminasen en la forma que menos daño causasen al Templo. Contando con todas estas circunstancias, en Madrid se consideró que el proyecto presentado -con toda probabilidad el de Luque- resolvía con bastante acierto, "dentro de lo posible", dicha aspiración y podía ser aprobado ${ }^{23}$.

Tras la aprobación inicial, la Academia de San Fernando aún hizo ciertas observaciones al proyecto: la posibilidad de estudiar la reducción de la altura de la parte a adicionar y la propuesta de demolición del pequeño cuerpo adosado a la fachada de poniente, que sólo se utilizaba para retretes que podían ubicarse en la habitación que les servía de ingreso. En cuanto a esta segunda observación, se consideraba que supondría un beneficio económico, dada la posibilidad de reutilizar los materiales procedentes del derribo; y otro beneficio estético, facilitando la vista de la fachada de poniente al dejar libre el primer tramo de las naves del cuerpo de la Iglesia. El informe finaliza manifestando la conveniencia de declarar la Catedral de Sevilla monumento nacional ${ }^{24}$.

La realidad es que las obras se comenzaron y ejecutaron entre 1923 y $1929^{25}$, siguiendo -en sus líneas generales- el proyecto que Francisco Javier de Luque firmó en 1921 y sin incluir las modificaciones propuestas por la Real Academia de Bellas Artes de San Fernando. Con certeza sabemos que en octubre de 1926 faltaban por librar partidas económicas, incluidas en el presupuesto primitivo, por valor de $136.161,14$ pesetas ${ }^{26}$.

Si comparamos el proyecto de Luque con la fábrica construida tal y como hoy se nos presenta, es posible concluir que se respetaron las líneas generales de aquél, si bien se modificaron algunos detalles, tales como parte de las molduras o los pináculos piramidales -posiblemente inspirados en el frontero Archivo de Indias-, convertidos en flameros, elementos más acordes con la Catedral dada su

23. Ibid., p. 197.

24. Ibid., pp. 197-198.

25. LUNA FERNÁNDEZ-ARAMBURU, R. y SERRANO BARBERÁN, C., op. cit., p. 48.

26. A.G.A. "Unidades de obra que integran las partidas que faltan por aprobar de las comprendidas en el proyecto que con fecha 6 de mayo de 1921 se formuló para la terminación de la fachada sur de la Santa Iglesia Catedral de Sevilla", documento firmado por Francisco Javier de Luque el 2 de octubre de 1926. Vid. nota 1. 
utilización en otras zonas renacentistas y barrocas. Independientemente del posterior análisis, que brevemente realizaremos, de los criterios de restauración aplicados en el ejemplo concreto que nos ocupa, el diseño de Luque, en sí mismo, merece una valoración, en cuanto a solución y composición meramente arquitectónicas, altamente positiva. Lo que podía haberse convertido en una pesada construcción con un remate claramente añadido y forzado, resultó transformarse en una obra armónica, correcta y de apariencia unitaria.

El historicismo preponderante por estos años, que conformaba el eje central de la formación de los arquitectos en las Escuelas de Arquitectura, les proporcionó a dichos profesionales una enorme habilidad en la utilización de los lenguajes artísticos procedentes del pasado que, combinada con la libertad de actuación que se les permitía en este tipo de obras, dieron resultados francamente sorprendentes dadas, a la vez, su novedad -su reciente ejecución- y su, por tanto, falseada -pero correcta- historicidad. Aplicaron su creatividad y sus conocimientos en función y provecho -así, al menos, lo creían- del edificio en el que habían de intervenir, dejando un tanto al margen su propia personalidad artística, la cual pasaba pronto al anonimato y al olvido, dada la cohesión y coherencia del resultado obtenido en cada edificio en cuestión. Y ello ha ocurrido en Sevilla y fuera de nuestra ciudad con edificios tan variopintos y representativos como la Plaza de Toros de la Real Maestranza ${ }^{27}$ o el teatro romano de Mérida ${ }^{28}$. En ningún caso de los citados es posible achacar la inadvertencia de sus intervenciones a que las mismas no fueran sustanciales, es decir, a que dichos artífices no modificaran prácticamente la esencia de dichas construcciones, al menos como eran conocidas hasta entonces. Modificaron o transformaron dichas fábricas sin que ello se perciba en aquéllas con claridad hasta que se localizan las fuentes documentales que vienen a confirmar, ratificar y clarificar sus actuaciones.

Nos hemos referido a que los arquitectos que, como Luque, actuaban en restauraciones o intervenciones dejaban al margen su propia personalidad artística. La expresión no es del todo correcta en tanto que su personalidad artística, su concepción del Arte, de la Arquitectura, era exactamente la que aplicaban en sus obras. Dicha afirmación debe ser matizada. Estos profesionales tenían una con-

27. GÓMEZ DE TERREROS GUARDIOLA, M.V.: "La Real Plaza de Toros. Evolución arquitectónica", en PALOMERO PÁRAMO, J.M. y otros: La Real Maestranza de Caballería de Sevilla. Este trabajo, en prensa, analiza el proceso constructivo de la plaza de toros de Sevilla, incluida la construcción de las nuevas localidades de tendido sobre las antiguas, obra realizada en la segunda década de nuestra centuria bajo la dirección de los arquitectos José Sáez y López y Aníbal González Álvarez-Ossorio.

28. La primera fase de restauración del frente de la escena del teatro romano de Mérida la realizó el arquitecto sevillano Antonio Gómez Millán, entre 1916 y 1925. Su estudio ha quedado recogido en GÓMEZ DE TERREROS GUARDIOLA, M.V.: Antonio Gómez Millán (1883-1956): una revisión de la arquitectura sevillana de su tiempo, Sevilla, 1993, pp. 114-141. 
cepción de su trabajo en la que la individualidad, la novedad, la vanguardia contaban con menos peso específico que en nuestros días. El edificio a restaurar o reformar, su entorno, la colectividad, la ciudad, los más variados lenguajes históricos -no necesariamente localistas- y, sobre todo el carácter y el estilo de la fábrica original eran factores a tener en cuenta. En consecuencia, aplicaban la creatividad propia de su tiempo que, por responder a criterios distintos a los nuestros, nos es difícil, en ocasiones, percibir y analizar. Lo que en su momento pudo valorarse como una modificación de un paisaje urbano, hoy se puede considerar como poco novedoso o creativo desde nuestra propia perspectiva postmoderna. Es lo mismo que le ocurre al observador, al turista o al paseante profano en temas de arquitectura cuando -aún hoy- recorre la actual Avda. de la Constitución de Sevilla, percibe los edificios historicistas -prácticamente contemporáneos al proyecto de Luque- que la conforman y los analiza y clasifica como arquitectura típica e histórica sevillana, cuando en su momento fueron causa de relevantes pugnas en el seno de la Real Academia de Bellas Artes de Santa Isabel de Hungría precisamente por su exotismo e inadecuación al entorno.

Hoy ya no podemos condenar estas obras de "restauración en estilo"-derivada de las interpretaciones de Viollet-le Duc-, ni el historicismo ecléctico de su tiempo, como "pastiches", "revivals" o "falsos históricos". Como apunta A. Capitel ${ }^{29}$ son el producto de una época, una aportación histórica concreta y, como tal positiva, siempre que se logre actuar correctamente en el edificio. Es preciso tener en cuenta que en aquella época el carácter artesanal de las obras, su "autenticidad constructiva", en gran parte, se mantuvo. Por tanto en el proyecto de Luque hay que valorar tanto su fidelidad a la fábrica preexistente, como su calidad independiente como diseño propio.

29. Vid. CAPITEL, A.: Metamorfosis de monumentos y teoriás de la restauración, Madrid, 1988, pp. 20-21 y 27-28. 


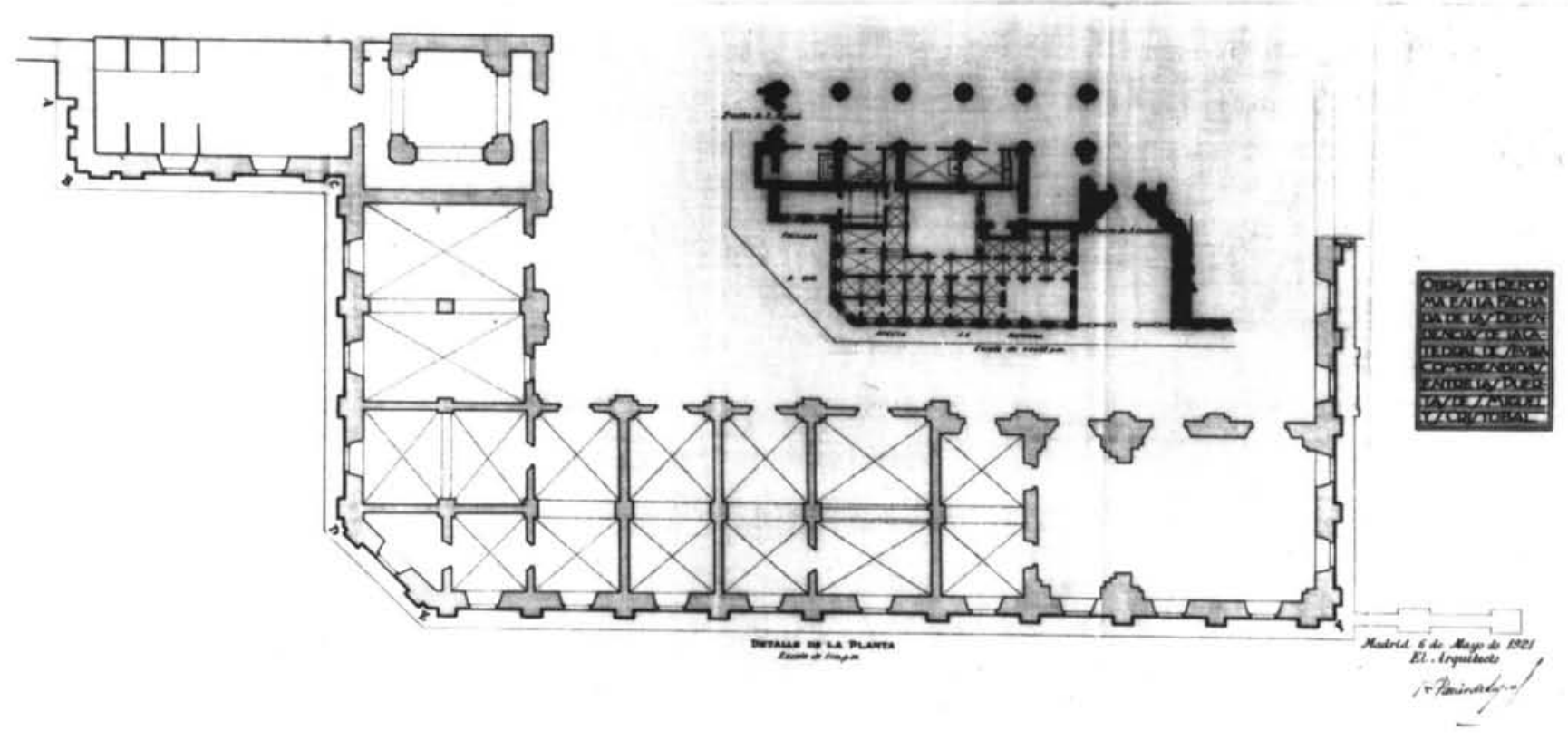

Lám. 1.

Plantas de la zona suroeste de la Catedral de Sevilla, Francisco Javier de Luque, 1921 (Archivo General de la Administración). 

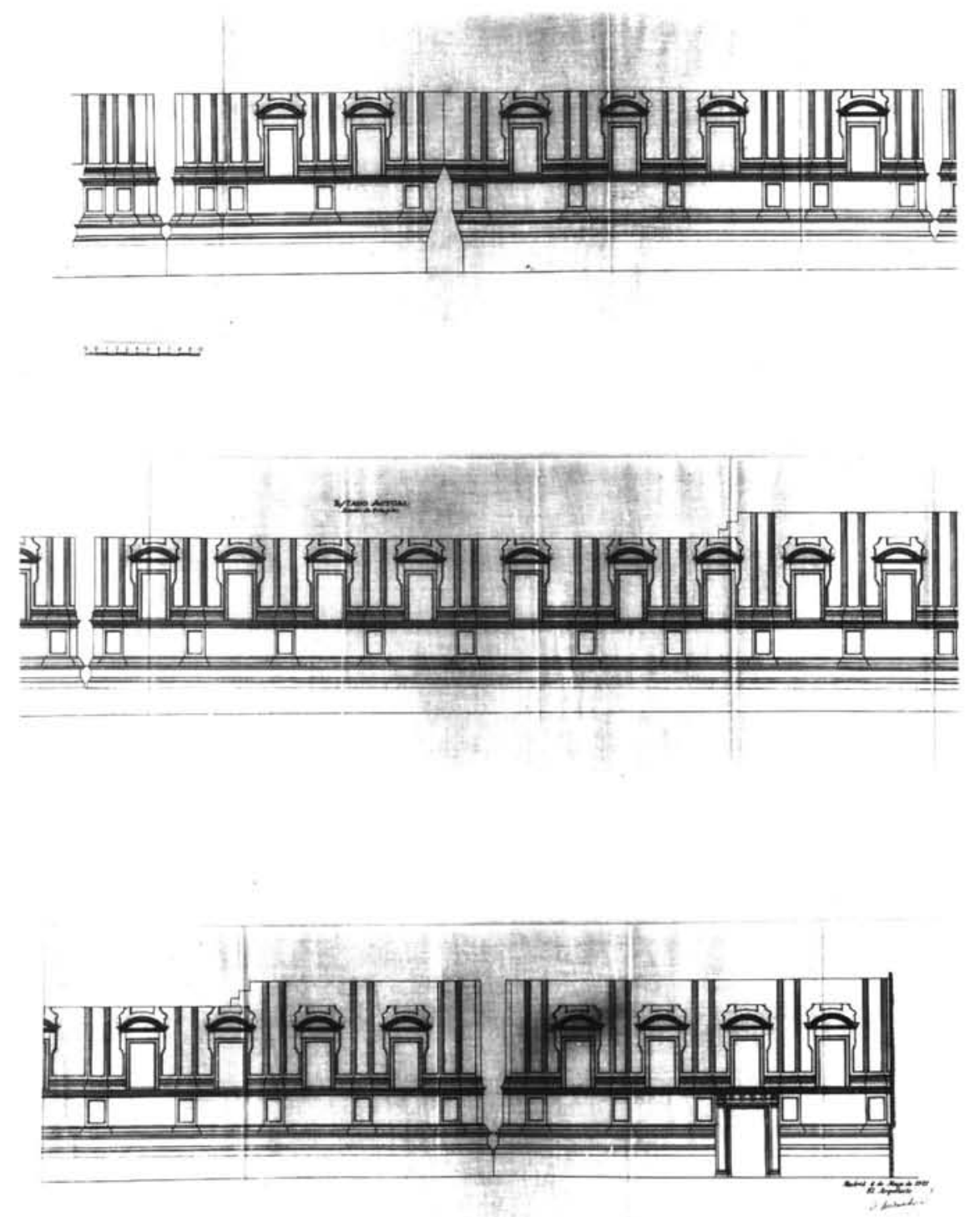

Lám. 2.

Plano del "estado actual" del pabellón del ángulo suroeste de la Catedral de Sevilla, Francisco Javier de Luque, 1921 (Archivo General de la Administración). 

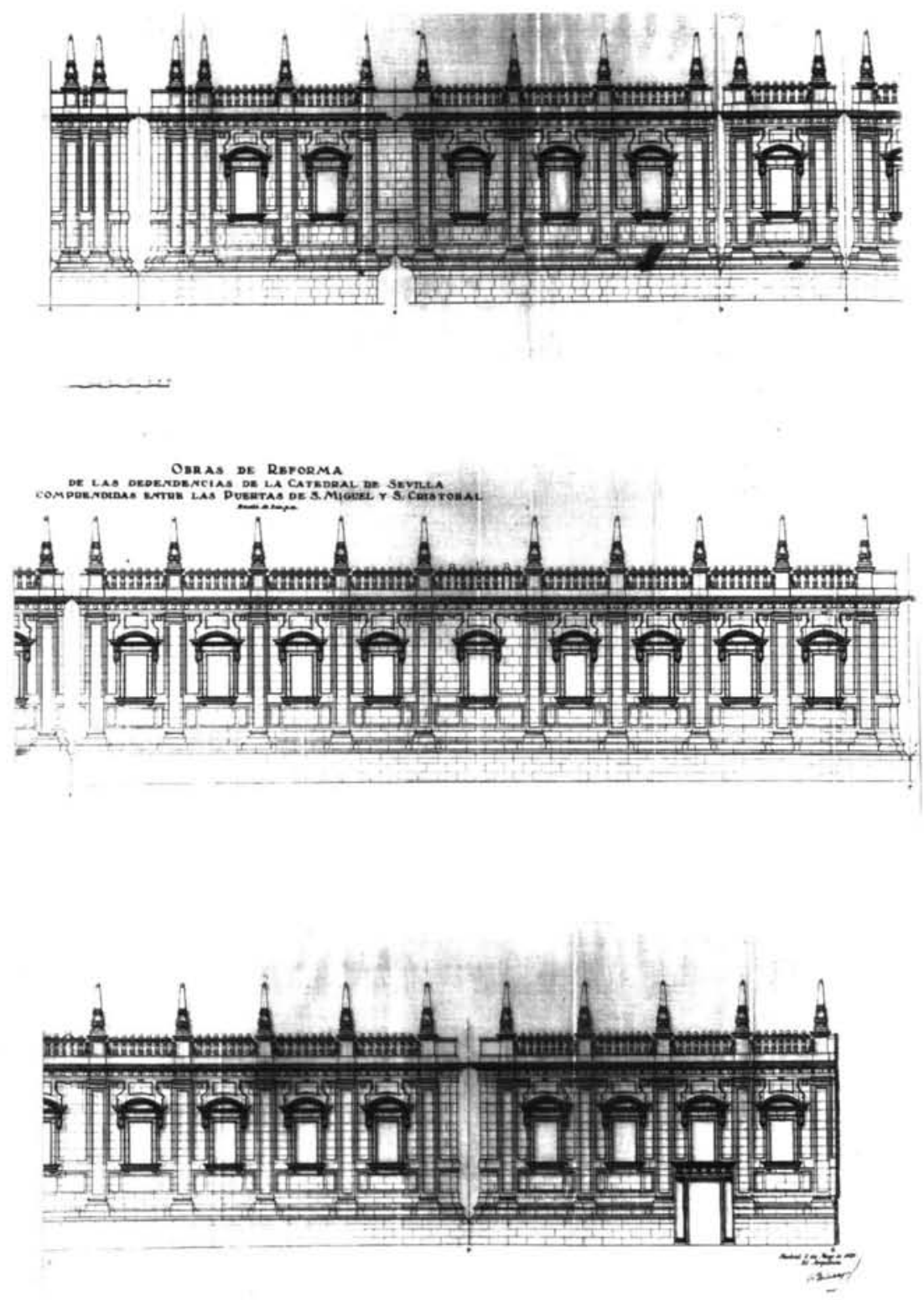

Lám. 3.

Alzado con las reformas proyectadas en las dependencias de la Catedral comprendidas entre las puertas de San Miguel y San Cristóbal, Francisco Javier de Luque, 1921 (Archivo General de la Administración). 


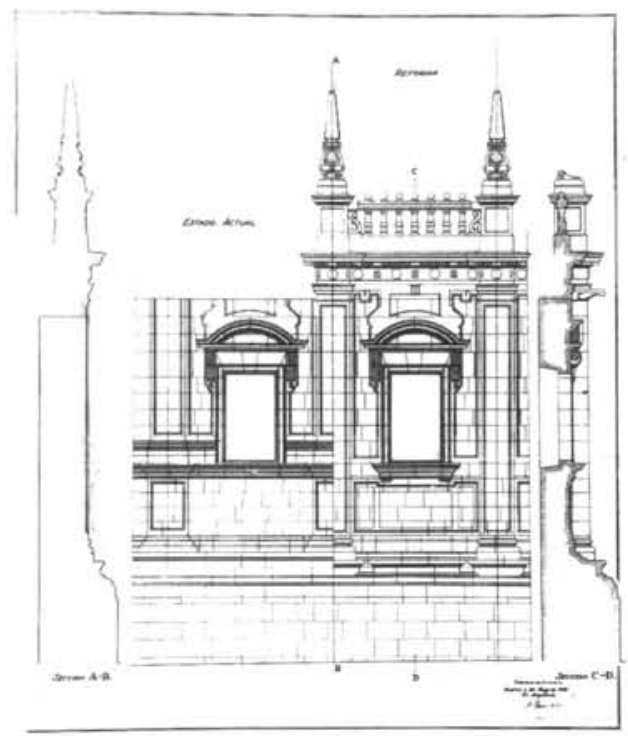

Lám. 4.

Plano de detalles del proyecto de terminación de la fachada suroeste de la Catedral de Sevilla, F.J. de Luque, 1921 (Archivo General de la Administración).

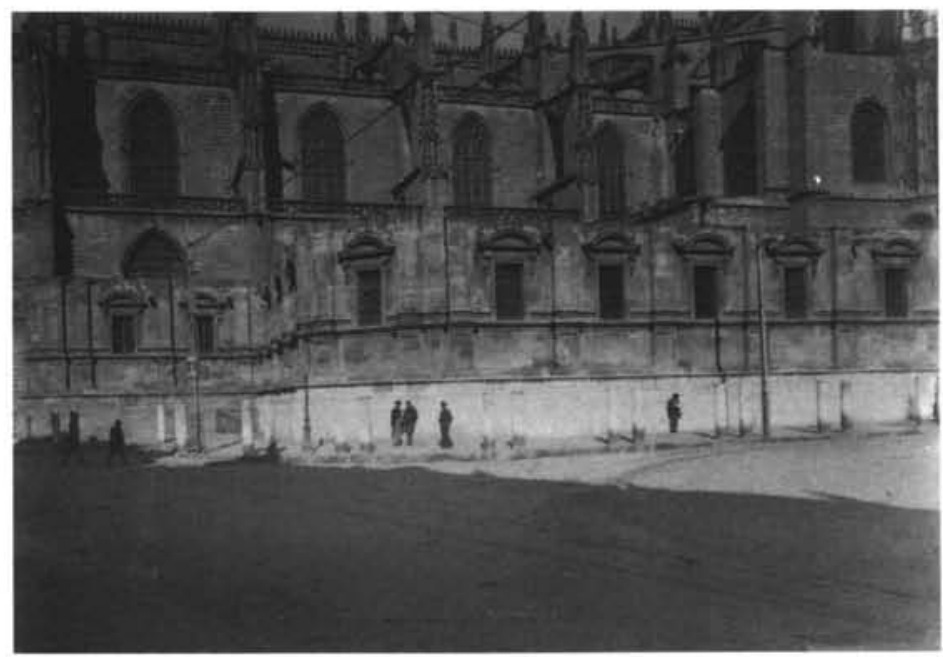

Lám. 5.

Estado del edificio antes de las obras emprendidas por F.J. de Luque (Archivo General de la Administración). 


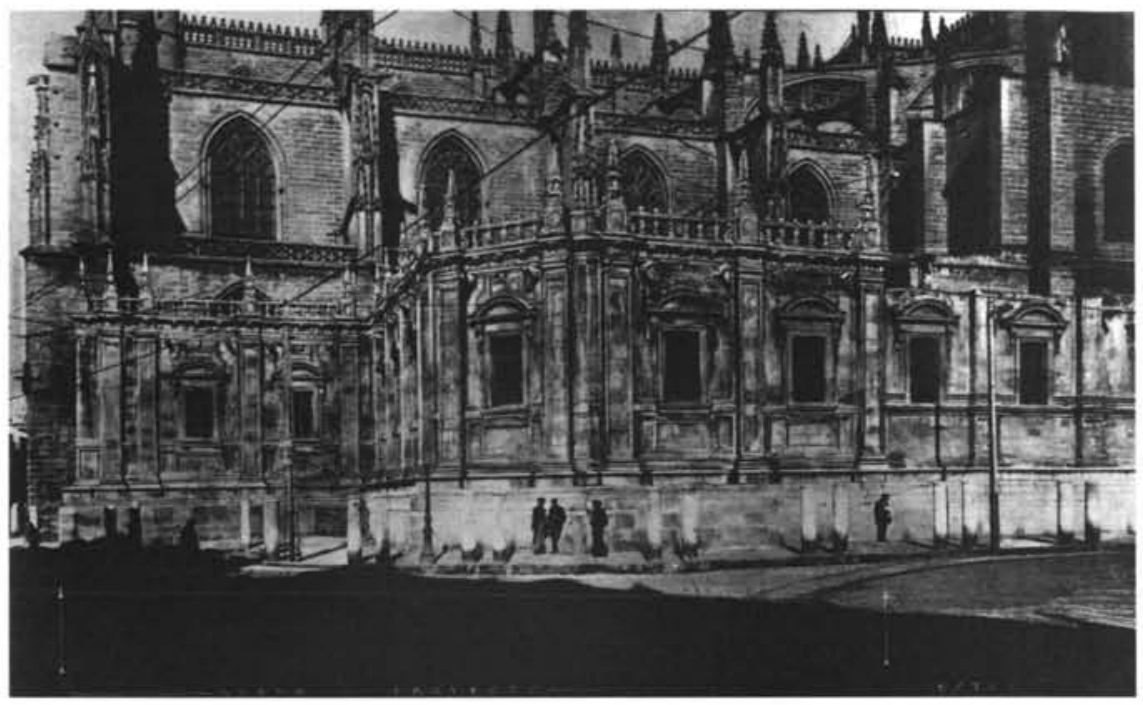

Lám. 6.

Fotomontaje presentado junto al proyecto de obras de terminación de la fachada suroeste de la Catedral de Sevilla por F.J. de Luque (Archivo General de la Administración).

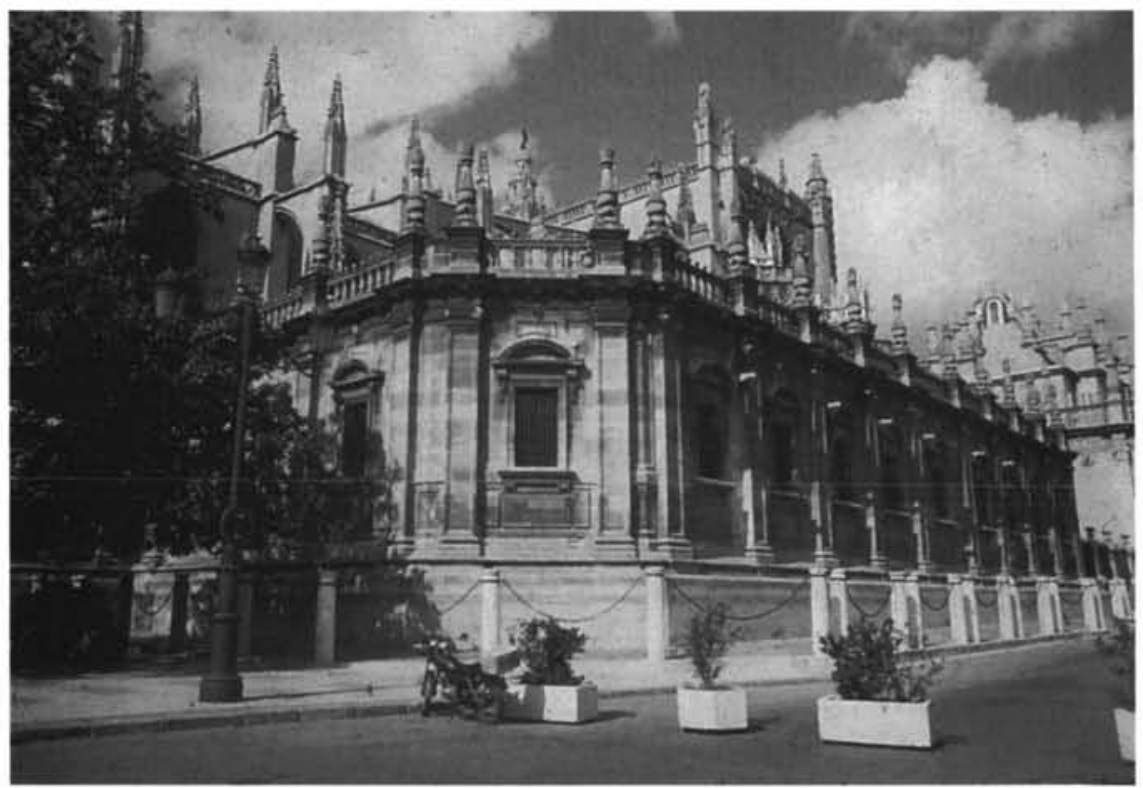

Lám. 7.

Fotografía actual de la fachada suroeste de la Catedral de Sevilla. 